\title{
Synthesis and Characterization of Commercial Pure Titanium-nickel Alloy Behavior Reinforced With Titanium Diboride
}

O.E. Falodun ( $\sim$ segzy201@gmail.com )

Centre for Nanomechanics and Tribocorrosion, University of Johannesburg, South Africa.

Samuel R Oke

Federal University of Technology Akure

Peter A Olubambi

University of Johannesburg - Doornfontein Campus

\section{Research Article}

Keywords: Titanium, nickel, TiB2, dispersion, microstructure, wear

Posted Date: October 27th, 2020

DOI: https://doi.org/10.21203/rs.3.rs-96352/v1

License: (c) (i) This work is licensed under a Creative Commons Attribution 4.0 International License.

Read Full License 


\title{
Synthesis and characterization of commercial pure titanium-nickel alloy behavior reinforced with titanium diboride
}

Oluwasegun Eso FALODUN ${ }^{1 *}$, Samuel Ranti OKE ${ }^{1,2}$ and Peter Apata OLUBAMBI ${ }^{1}$

${ }^{1}$ Centre for Nanomechanics and Tribocorrosion, University of Johannesburg, South Africa.

${ }^{2}$ Department of Metallurgical and Materials Engineering, Federal University of Technology,

\author{
Akure, Ondo State, Nigeria. \\ *Corresponding E-mail: segzy201@gmail.com
}

\begin{abstract}
Commercial pure titanium alloy with $\mathrm{Ni}-\mathrm{TiB}_{2}$ ceramic additions $(5,10,15$ and 20 vol.\%) were synthesized through the spark plasma sintering approach with sintering temperature of $1000{ }^{\circ} \mathrm{C}$, the heating rate of $100^{\circ} \mathrm{C} / \mathrm{min}$, holding time of $5 \mathrm{~min}$ at a constant pressure of $50 \mathrm{MPa}$. The study investigated the effect of $\mathrm{Ni}_{-}-\mathrm{TiB}_{2}$ on the densification, phase change, microhardness, microstructure, and wear properties of the sintered titanium-based composites. Results showed that $\mathrm{Ti}-\mathrm{Ni}-\mathrm{TiB}_{2}$ composites relative density ranges from 97 to $99 \%$, while microhardness values increase with addition of nickel and titanium diboride from 228 to $587 \mathrm{HV}_{0.1}$. The microstructural evolution shows that pure titanium transformed from lamellar phase to equiaxed alpha phase upon addition of nickel alloy and further get refined with a distinct grain boundary comprises of titanium diboride around the boundaries. The average coefficient of friction for the titanium-based composite was higher for commercially pure titanium (0.73) while the addition of $\mathrm{TiB}_{2}$ exhibit $(0.66,0.63,0.58,0.55$ and 0.46 respectively) improvement in the wear behavior.
\end{abstract}

Keywords: Titanium; nickel; $\mathrm{TiB}_{2}$; dispersion; microstructure; wear 


\section{Introduction}

Titanium and titanium alloys have been utilized in different engineering applications because of their attractive properties, for example, low density, high specific strength, biocompatibility and exceptional corrosion resistance [1,2]. Despite the properties that titanium alloys with usage in various engineering applications, they are restrained for high-temperature applications usage due to their poor tribological properties. The way toward improving the mechanical properties of titanium alloys can be accomplished through the addition of various alloying elements, for example, alpha stabilizer, neutral, beta isomorph and eutectoid stabilizers. Nickel is beta eutectoid stabilizers which at high temperature, nickel and titanium alloy form intermetallic compounds which is ductile with better plasticity, high impact resistance and good damping properties [3-5].

Titanium diboride $\left(\mathrm{TiB}_{2}\right)$ have attracted increasing consideration from various researchers because of its various applications such as, cutting tools, wear applications, high-temperature structural materials and lightweight impact resistance protective layer material, because of its exceptional mechanical properties, for example, high melting point, high hardness, high Young's modulus, good abrasion resistance, high strength, thermal conductivity and chemical stability [6-8].

Metal matrix composites have shown remarkable potential for the structure and improvement of innovative new advanced materials which is achieved in consolidating ceramic as methods for strengthening metal matrix to improve its mechanical properties [9]. Metal and its alloy don't completely possess some degree of properties required in essential materials and this driven the improvement through metal matrix composites by reinforcing it either utilizing particulate or ceramic into the metal matrix $[10,11]$.

Spark plasma sintering is another sintering method that permits sintering of powders at lower sintering temperatures, rapid heating, holding and cooling time when identified with different conventional sintering technique [12]. In SPS process, because of its highlights, such as, raw powders and graphite die are directly heated with a pulsed current which prompts the making of sparks between the powder particles as a result generate spark discharge and mass transfer which can be accomplished rapidly and further simplicity expulsion of oxide contaminants from the surface of the particles [13]. The application of pressure can deform the particles and accordingly permitting the production of stronger connections between neighboring particles whereby the 
electrical field can help in atom diffusion [14]. Spark plasma sintering methods have demonstrated that rapid time and heating rates consolidation has been advantageous in preventing grain development and control of microstructures thereby retaining the grain size and achieving improvement in mechanical properties $[15,16]$ with high relative densities in a short timeframe.

In this study, $\mathrm{TiB}_{2}$ particle-reinforced titanium-nickel based composites were successfully created utilizing a spark plasma sintering method. The effects of $\mathrm{Ni}$ with ceramic particle $\left(\mathrm{TiB}_{2}\right)$ additions at the distinctive volume per cent composition on the densification, hardness, microstructures and wear behaviour were examined.

\section{Experimental procedure}

Titanium, nickel and titanium diboride powders were milled using a planetary ball mill (Retch 400 PM) with alumina cup and balls for $8 \mathrm{~h}$ at an interval of $10 \mathrm{~min}$, powder to ball ratio of 10:1 and rotation speed of $150 \mathrm{rpm}$ were used during the milling process. These parameters were selected to avoid powders from been heated up to prevent cold welding of the powders and avoid unwanted phase formation that could occurs within the powders during milling operation. The admixed powders were solidified utilizing spark plasma sintering machine (HHPD-25 FCT Germany) and further compacted in graphite die with inner distance across of $20 \mathrm{~mm}$ and $5 \mathrm{~mm}$ thickness at a steady temperature of $1000^{\circ} \mathrm{C}$, heating rate of $100{ }^{\circ} \mathrm{C} / \mathrm{min}$, applied pressure of $50 \mathrm{MPa}$ and holding time of 5 mins under a vacuum atmosphere.

The density of the sintered samples was estimated utilizing using Archimedes technique as per ASTM B962-15 standard. The titanium matrix composites were precisely weighed both in air and de-ionized water utilizing an electronic measuring balance. Microhardness Vickers machine (FALCON 500 series) was utilized to do the hardness test at a full load of $300 \mathrm{gf}$ with a dwell time of $15 \mathrm{~s}$. The phase identification of the sintered composites was performed utilizing XRD PW1710 Philips diffraction with $\mathrm{Cu}$ target $\mathrm{K} \alpha$ radiation at $40 \mathrm{kV}$ and $40 \mathrm{~mA}$. While X'pert Software was utilized to identify every constituent phases of the sintered composites. The polished samples were etched utilizing Kroll's reagent and further examined utilizing scanning electronic microscope (Vega/Tescan model) equipped with an energy dispersive range (EDS) analyzer with an accelerating voltage of $15 \mathrm{kV}$. 
The wear test was completed utilizing a tribometer pin-on-disk friction module procedure. A stainless-steel ball with $6 \mathrm{~mm}$ in diameter was utilized as a counter face rubbing against the titanium-based composite. A load of $10 \mathrm{~N}$ was applied with a rotational speed of $300 \mathrm{rpm}$ under a dry rotary condition at ambient temperature. The mean coefficient of friction (COF) was determined and reported for all materials. The volume loss (V) of the titanium-based composites was determined utilizing the below equation 1 :

$$
V=\frac{\Delta w}{\rho}
$$

Where $\Delta \mathrm{w}=$ weight before test-weight after test and $\rho=$ density of the titanium-based composites. The wear rate $(\mathrm{W})$ was then determined to utilize the below equation 2 :

$$
W=\frac{\Delta w}{L . \rho . F}
$$

Where $\Delta \mathrm{w}$ is weight loss difference (before-after tests), $\rho$ is density of the titanium-based composites, $\mathrm{L}$ is sliding distance and $\mathrm{F}$ is the applied force.

\section{Results and discussion}

3.1 Characterization of starting and admixed powders

Figure 1a-c shows the SEM morphology of titanium, nickel, titanium diboride and admixed powders. Figure 1a shows titanium alloy powder is spherical and non-porous with a few agglomerated satellites adhering to the bigger particles while titanium diboride is little irregular particles. Figure 1d-e revealed the micrograph of the composite containing 5 vol.\% Ni and 20 vol.\% TiB2. The powders resulted in uniform relatively dispersion within the surface of the titanium alloy particles. Also, the shape of the titanium particles can be found to have change a little with some agglomerated particles which might be due to cold welding during the mixing operation. The process of powder blending approach is typically noticeable by the homogeneity of the blended powder [17]. Figure if revealed the EDX of the element present after the milling process. After mechanical alloying, the grain size of all powders is reduced, and the titanium particles are protected by fine grains of $\mathrm{Ni}$ and $\mathrm{TiB}_{2}$ particles. The decrease of grain size, homogenous dispersion of particles because of changes during processing shorten the dispersion way and increasing defects density are significant points of interest of mechanical alloying [18]. 

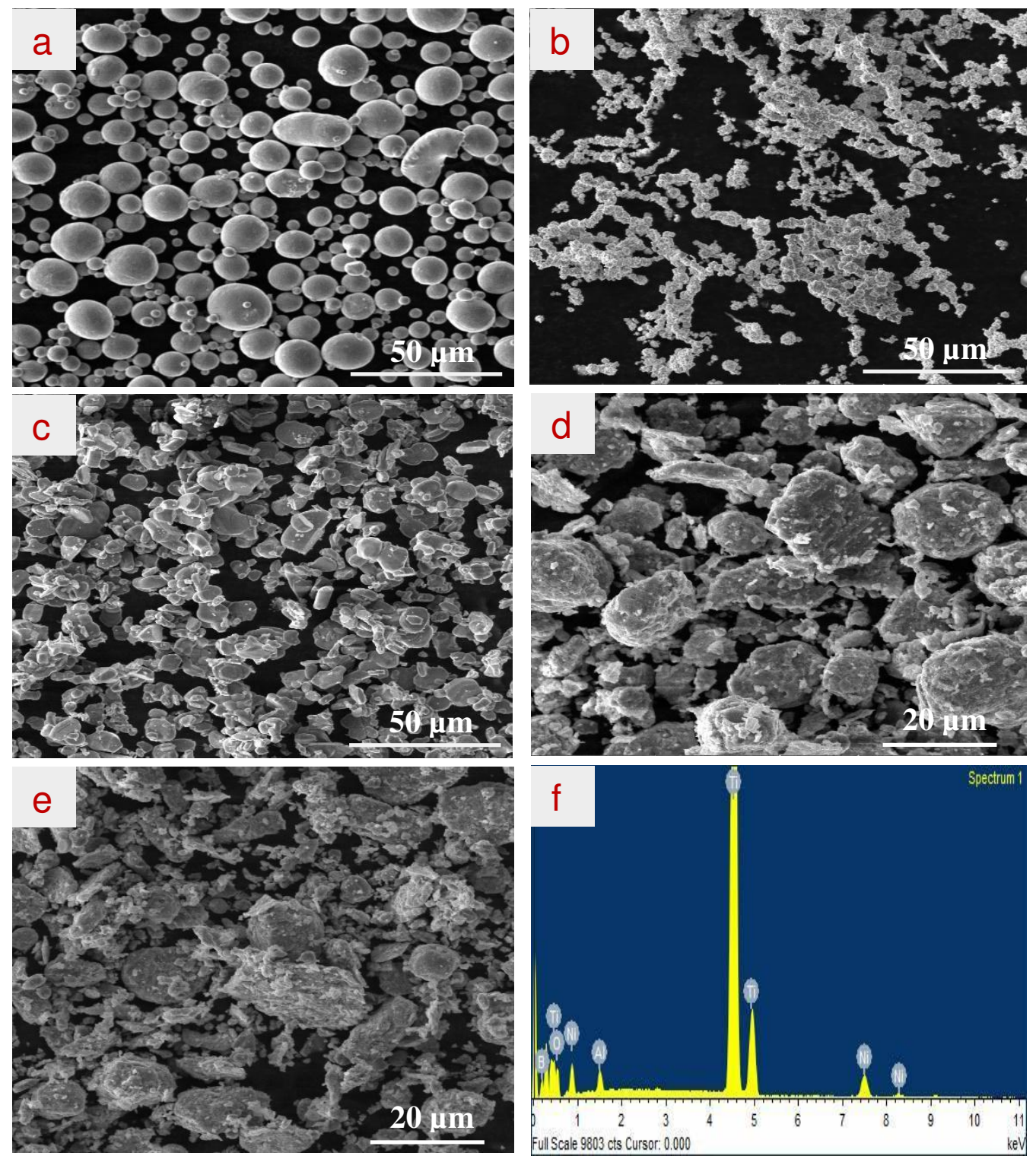

Fig. 1. SEM morphology of the powders; (a) Commercial pure titanium, (b) Nickel, (c) Titanium diboride, (d-e) admixed powders of Ti-Ni with 5 and 20 vol.\% $\mathrm{TiB}_{2}$ and (f) EDX of the admixed powders.

The XRD spectra of the blended powders with different amount of titanium diboride have shown in Fig. 2 with controlled peak intensity. The blended powders present some similar patterns and some new phases formation after mixing of the powders while remained the $\alpha$ phase. It was observed that the $\alpha$ phase is characterized by the (100) reflections at a peak position of $2 \theta=34.27$ and the diffraction peak was slightly decrease upon the increase of the reinforcement in the whole composite material. 


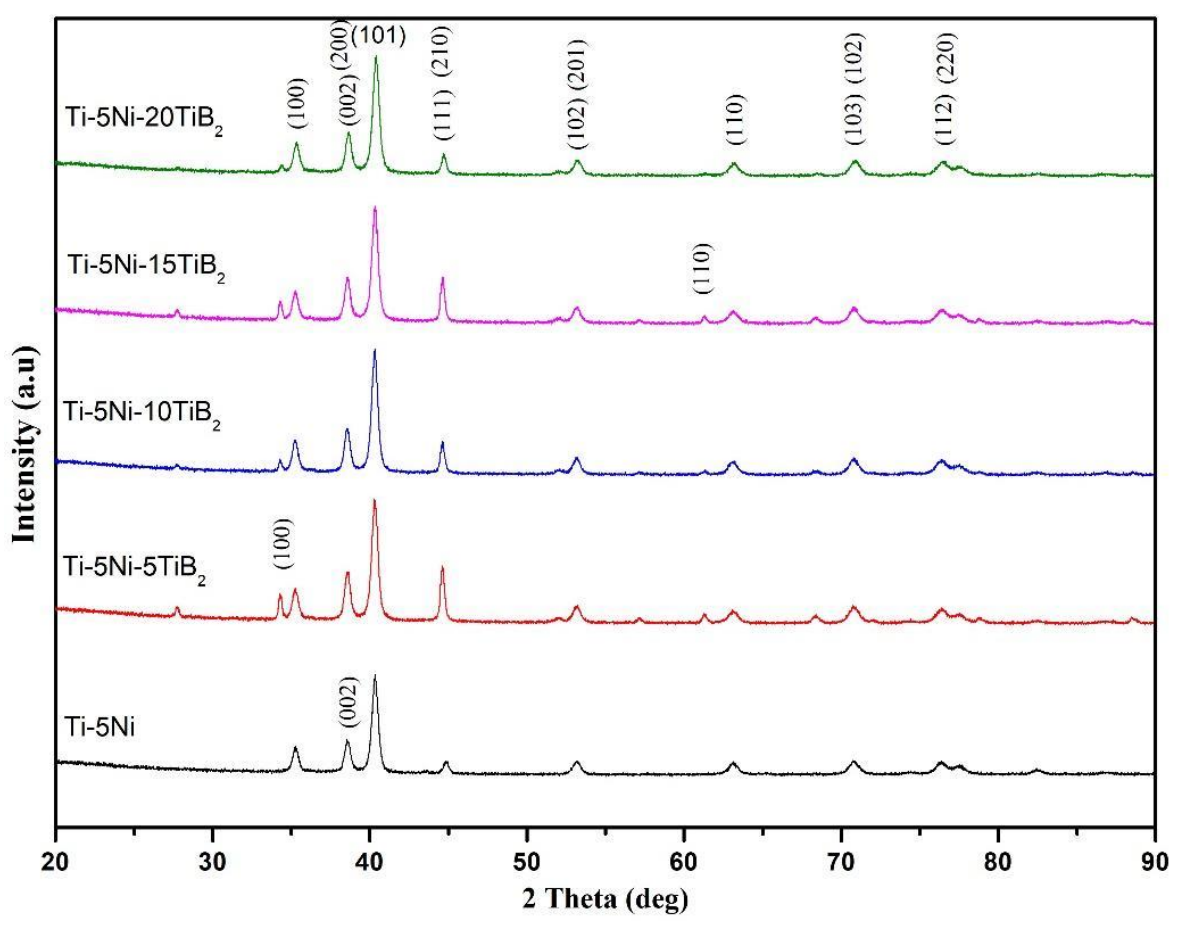

Fig. 2. XRD patterns of the admixed composite powders

Figure $3 \mathrm{a}-\mathrm{c}$ revealed the consequence of sintering temperature, displacement and shrinkage rate as a function of time for the sintered composite material. The sintering temperature of $250{ }^{\circ} \mathrm{C}$ was kept for few minutes and then raise up to $1000{ }^{\circ} \mathrm{C}$ and held for $5 \mathrm{~min}$ and further cooled down to room temperature. Figure $3 \mathrm{~b}$ display an increase in displacement as the temperature raises which is because of rearrangement of the powders with the effect of pressure exerted upon it that causes discharge of trapped air and gas within the compact. The sintering processes goes together with neck growth due to the collective effects of evaporation and condensation which rises sintering temperature [19]. Thus, an increase in displacement behaviour shows that transformation took place in the physical state and structure of the powders. Figure $3 \mathrm{c}$ demonstrate the shrinkage rate that occur during the total sintering time of the spark plasma sintering process. The shrinkage rate display two distinct peaks. Stage 1 shows a combination of early rearrangement of the powders, gas removal, formation of spark presence and the shrinkage rate arose with an increase in temperature causing bonding between the powder particles which resulted in melting, local deformation of particles arrangement, growth of the sintering necks at contact zone and plastic flow movement [20]. At the second stage, which signifies a little deforming zone because of the short holding time of 5 min while the sintering operation ends with character of decrease in shrinkage rate. 

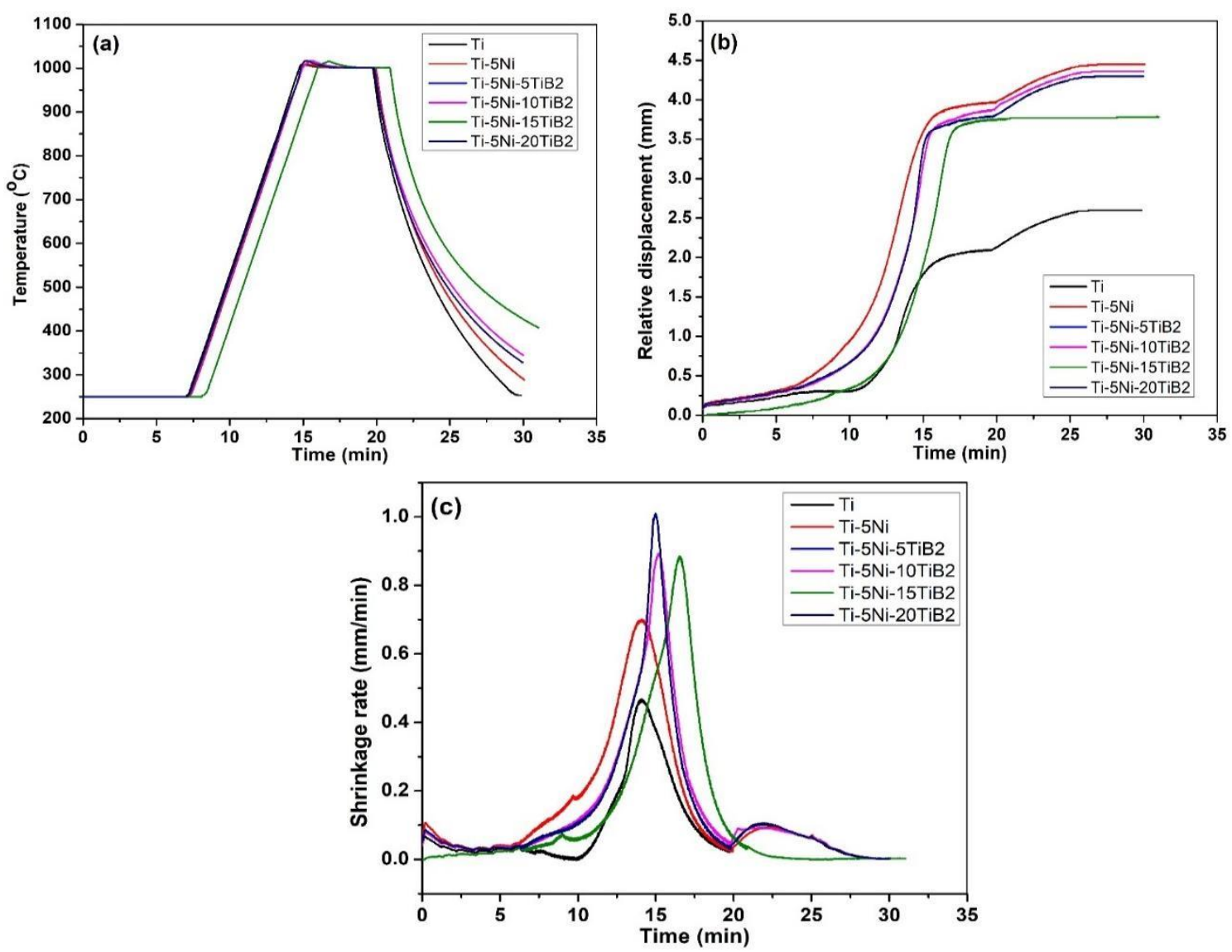

Fig. 3. Sintering parameters during SPS process against time: (a) sintering temperature, (b) relative displacement and (c) shrinkage rate.

\subsection{Density and hardness measurement of sintered titanium-nickel based composite}

Figure $4 \mathrm{a}$ shows the effect of sintering parameters on the densification behavior. The relative density decreased with the addition of reinforcement from 99 to $97 \%$. However, the incorporation of ceramic reinforcement into materials tends to decrease their density [21]. The decrease shows that some few porosities might be present in the composite material. Figure $4 \mathrm{~b}$ shows the microhardness value which increases as the reinforcement is addition in different percentage. The increase in microhardness can be attributed to the high hardness characteristics of the additional ceramic additives which prevent dislocation movement and give a good resistance to plastic deformation of the titanium matrix composites [22]. Also, the increase in hardness of the titanium matrix composite can be attributed to the homogenous dispersion of the particles. 

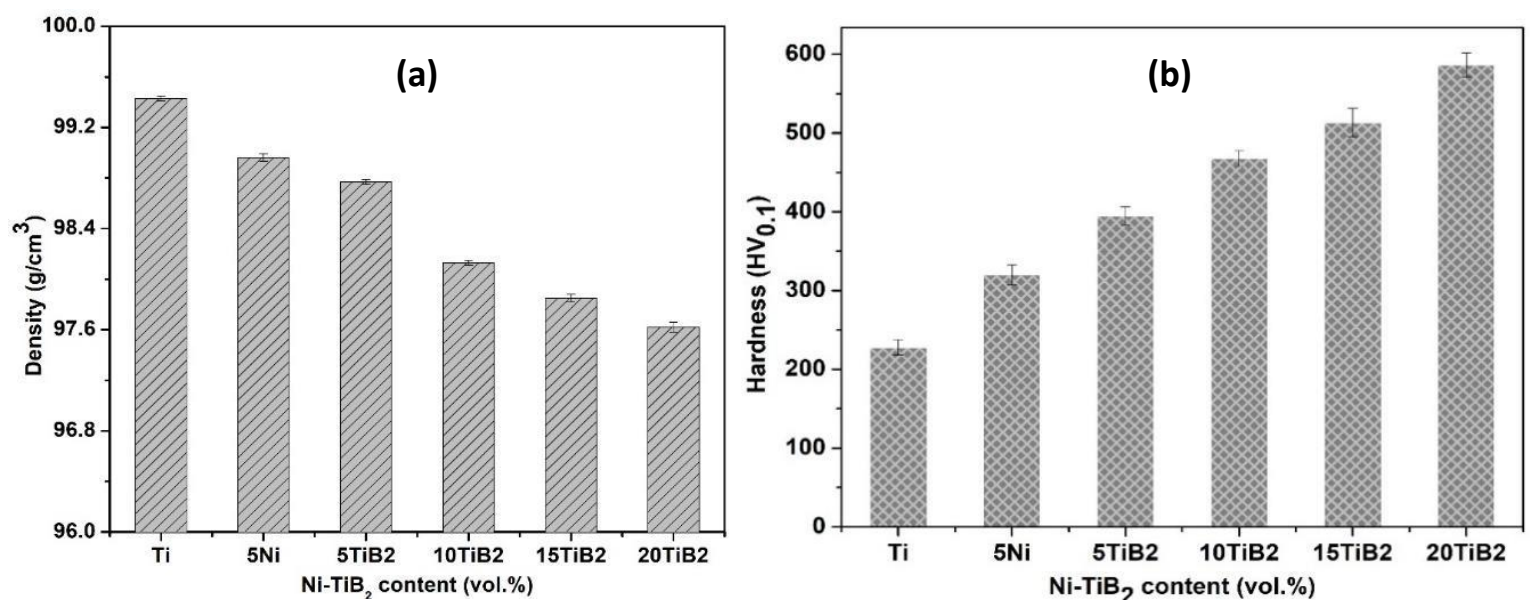

Fig. 4(a) Relative density and (b) Microhardness values of the sintered titanium-based composite.

\subsection{Microstructural characteristics of the titanium-nickel based composite}

Figure 5 shows the SEM micrograph of the produced titanium-based composites (Ti reinforced with $5 \% \mathrm{Ni}$ and 5-20 vol.\% $\mathrm{TiB}_{2}$ ). Dispersion of the reinforcement should be detected in the titanium matrix and to prove that spark plasma sintering technology is actual to process these materials. This technique allows densification of the matrix with effective dispersion. However, some agglomerated particles should still be identified which might be due to high specific surface area of the particles which causes clustering. Figure 5b-f reveal that the microstructural evolution of pure titanium transformed from lamellar phase to equiaxed alpha phase upon addition of nickel alloy and further get refined with a distinct grain boundary comprises of titanium diboride around the boundaries. 

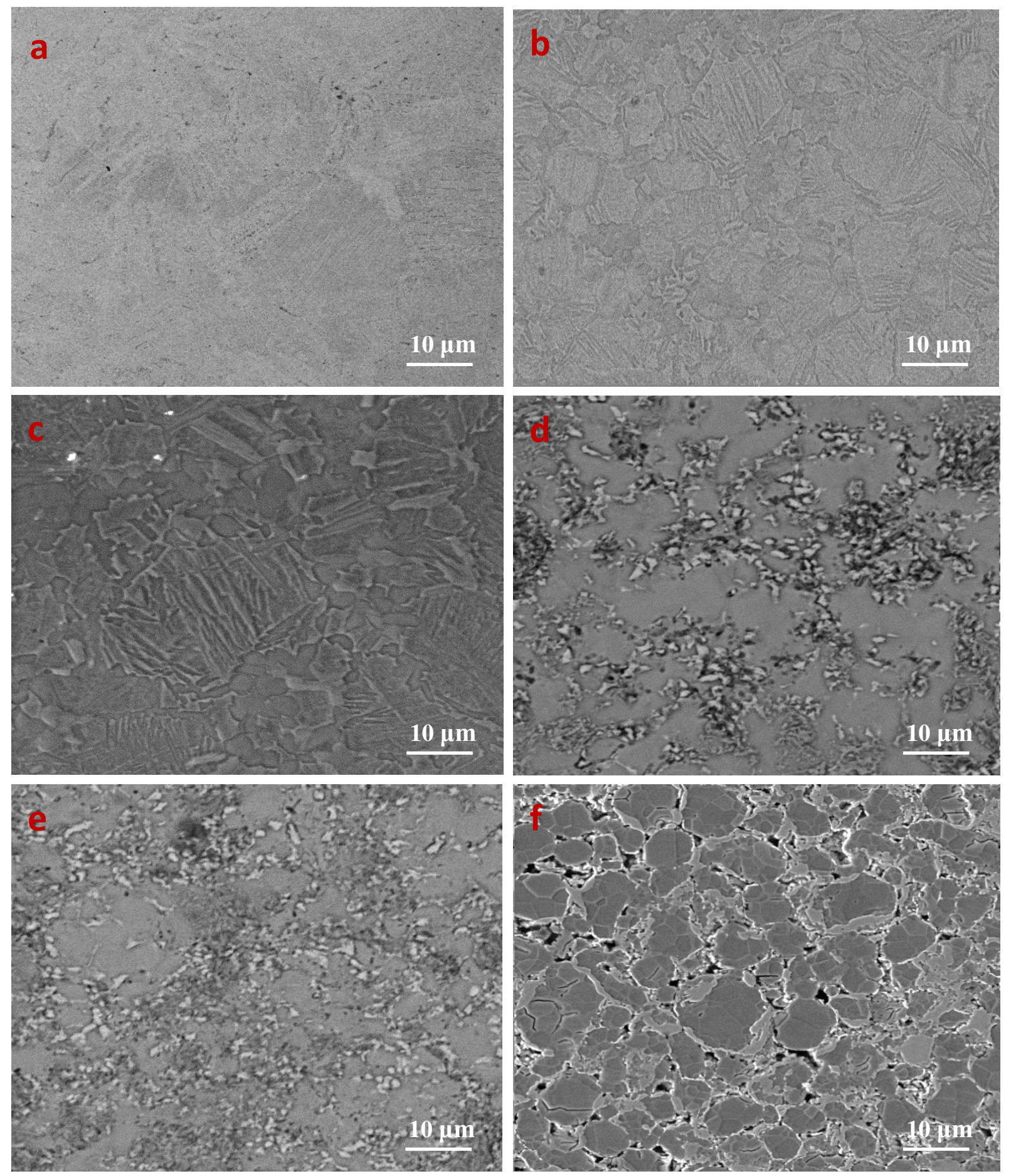

Fig. 5. SEM microstructure of sintered composites; (a) Ti alloy, (b) Ti-5 vol.\% Ni, (c) Ti-5 vol.\% Ni-TiB2, (d) Ti-10 vol.\% TiB2, (e) Ti-15 vol.\% TiB2 and (f) Ti-5 vol.\% Ni-20 vol.\% TiB2.

3.5 X-ray diffraction of titanium-nickel based composite

Figure 6 shows the XRD patterns of commercially pure titanium alloy and varying volume fraction of $\mathrm{TiB}_{2}$ with nickel carried out at a sintering temperature of $1000{ }^{\circ} \mathrm{C}$ and the respective miller 
indices. Addition of nickel into titanium alloy causes a reduction in the intensities peak, with a slight shift in the peaks which, could be as a result of high tensile stress of $\alpha$ phase [23]. However, diffraction peaks of the sintered titanium-based composite confirm the presence of both $\alpha$ and $\beta$ peak, which are predominantly phases [24]. On the other hand, an increase in the peak height with the addition of 5-20 vol.\% $\mathrm{TiB}_{2}$ was observed. Generally, the decrease in the peak height of the titanium-based composite could likewise be credited to the x-ray absorption effect [24]. Thus, some peaks were observed which are different from the primary titanium alloy such as (106), (303), (200) and (112) at $2 \theta=53.28^{\circ}, 63.49^{\circ}, 76.17^{\circ}$ and $77.62^{\circ}$ respectively.
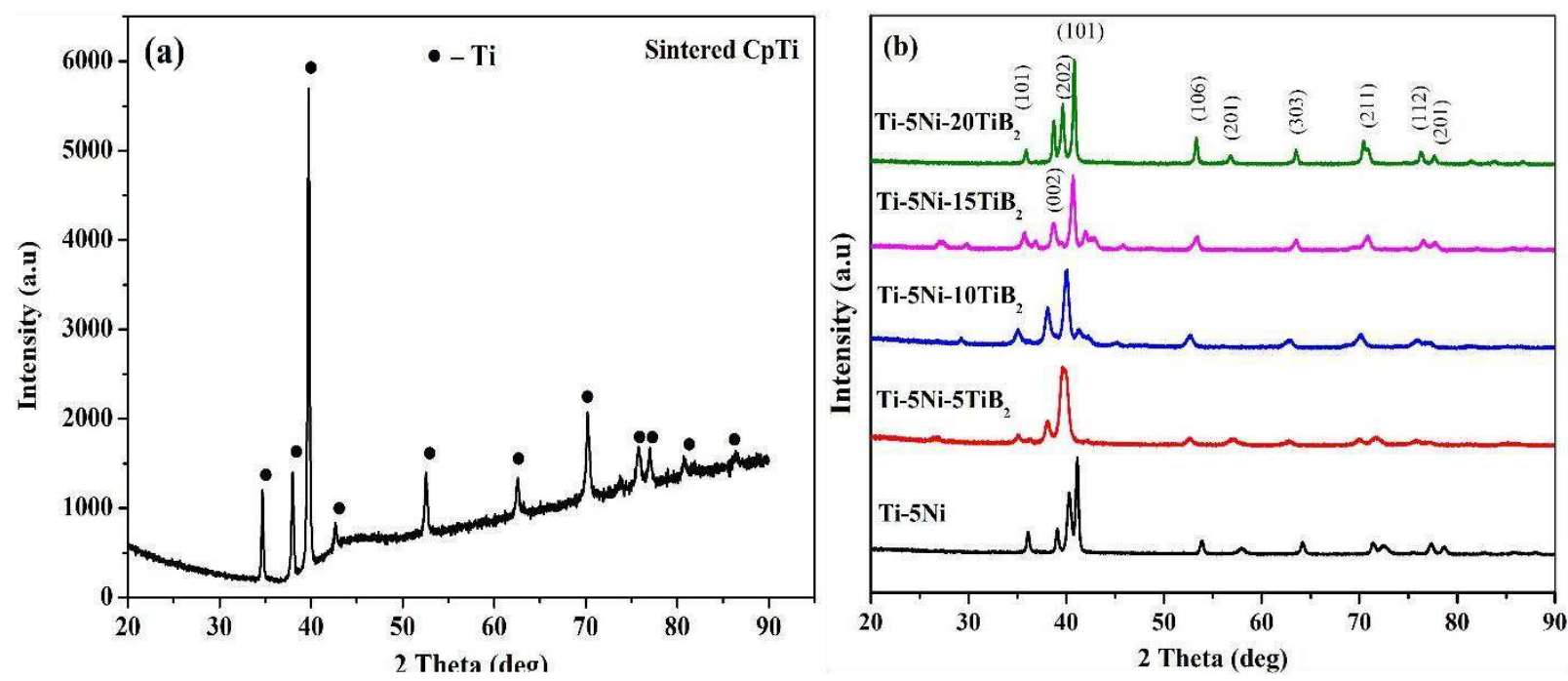

Fig. 6. XRD patterns of sintered titanium-based composite: (a) Titanium alloy and (b) varying volume fraction of $\mathrm{TiB}_{2}$.

3.6 Effect of reinforcement on wear behavior of the titanium-nickel based composite

Figure 7 shows the average coefficient of friction of composites at an applied load of $10 \mathrm{~N}$. It is clearly shown that the addition of 5 vol.\% Ni slightly decreases the coefficient of friction. Further addition of titanium diboride into the matrix exhibits a lower coefficient of friction compared to unreinforced commercial pure titanium. Reduction in the coefficient of friction upon addition of nickel and titanium diboride is because of lubricating action of $\mathrm{TiB}_{2}$ on the surface of the titaniumbased composite creating some layer on the rubbing surfaces which further diminishes slides taking place at the composite and ball contact surfaces [25]. The wear volume and wear rate of the titanium-based composites are presented in Fig. 7b-c. It is seen that the wear volume is responsive to the extent of the applied load. It is noticed that the wear volume decreases with increase in the 
reinforcement $\left(\mathrm{TiB}_{2}\right)$ content, which can be attributed to the hardness of titanium-based composites which displayed an increase as the reinforcement contents are added into the titanium alloy.
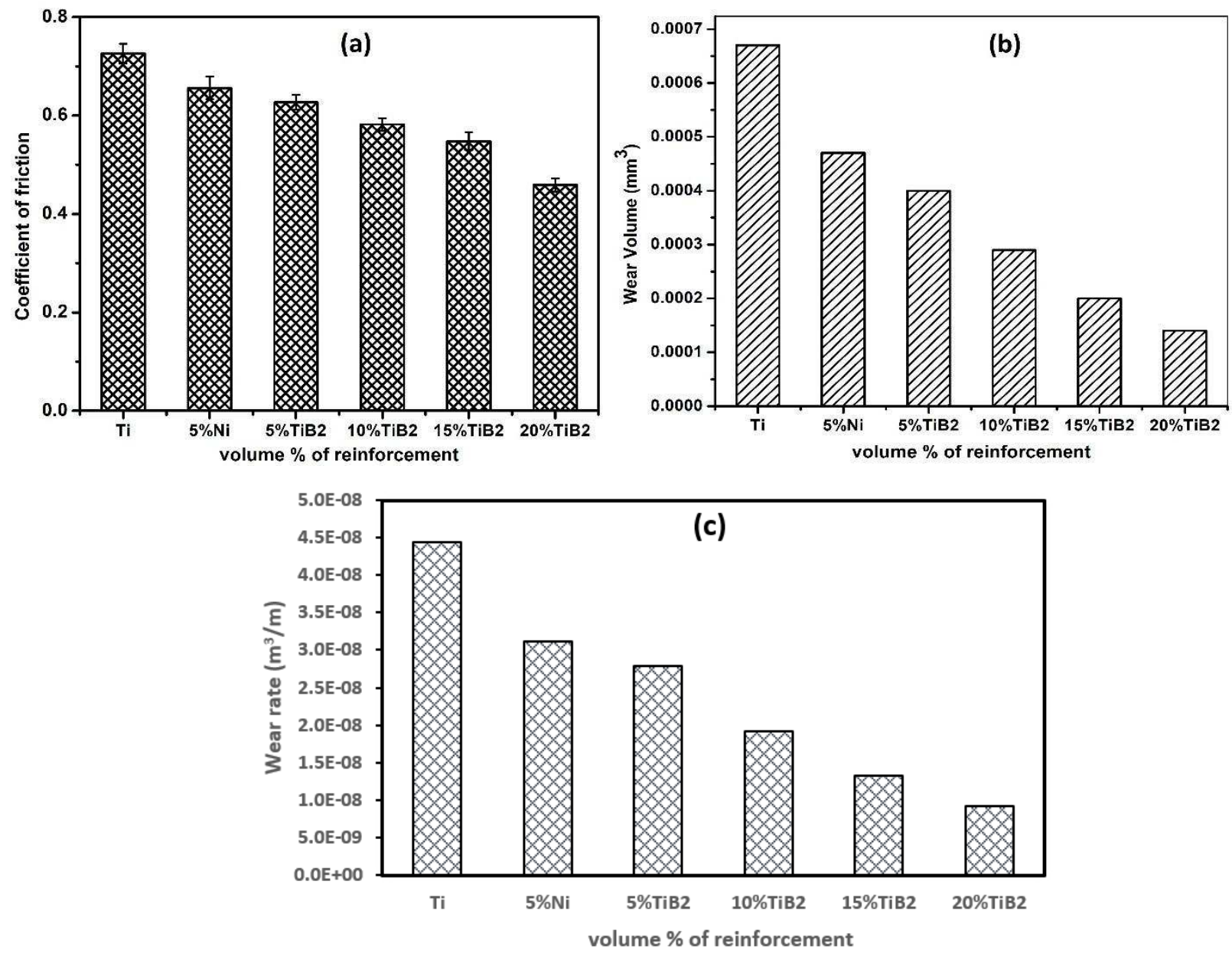

Fig. 7. Graph showing the effect of reinforcement: (a) coefficient of friction, (b) wear volume and (c) wear rate

\section{Conclusion}

1. Homogenous dispersion of $\mathrm{Ni}^{-} \mathrm{TiB}_{2}$ into the matrix alloy was accomplished. While the manufacture of titanium-nickel based composite from powder metallurgy utilizing spark plasma sintering method was consolidated.

2. Addition of alloying element and ceramic particles $\left(\mathrm{Ni}-\mathrm{TiB}_{2}\right)$ to the titanium matrix significantly influence through increasing the microhardness value and causing a transformation in the microstructure by hindering grain development and grain boundary movement. However, there was a decrease in the density of the produced titanium matrix composite with an increase in the concentration of reinforcement. 
3. The microstructural evolution shows the transformation from lamellar into an equiaxed phase with titanium diboride situated at the grain boundaries of the titanium matrix composite. There is additionally a good interfacial bonding between the titanium matrix and both $\mathrm{Ni}-\mathrm{TiB}_{2}$ support materials.

4. Titanium-nickel based composites exhibited good wear resistance when related to commercially pure titanium. Increase in the reinforcement addition displayed a lower coefficient of friction compared to titanium alloy.

\section{Acknowledgement}

The authors would like to appreciate the University Research Committee at the University of Johannesburg, South Africa and Faculty of Engineering and the Built Environment for financial support.

\section{References}

[1] Gurrappa I. Characterization of titanium alloy Ti-6Al-4V for chemical, marine and industrial applications. Materials Characterization 2003;51:131-9.

[2] Falodun OE, Obadele BA, Oke SR, Ige OO, Olubambi PA. Effect of TiN and TiCN additions on spark plasma sintered Ti-6Al-4V. Particulate Science and Technology 2020;38:156-65.

[3] Banerjee D, Williams JC. Perspectives on titanium science and technology. Acta Materialia 2013;61:844-79.

[4] Long M, Rack HJ. Titanium alloys in total joint replacement-a materials science perspective. Biomaterials 1998;19:1621-39.

[5] Muthuchamy A, Rajadurai M, Annamalai AR, Agrawal DK. Effect of Nickel Addition on Microstructure and Mechanical Properties of the Spark Plasma Sintered Ti-6Al-4V Alloy. Transactions of the Indian Institute of Metals 2019;72:2127-34.

[6] Jain A, Pankajavalli R, Anthonysamy S, Ananthasivan K, Babu R, Ganesan V, et al. Determination of the thermodynamic stability of TiB2. Journal of Alloys and Compounds 2010;491:747-52.

[7] Subramanian C, Murthy TSRC, Suri AK. Synthesis and consolidation of titanium diboride. International Journal of Refractory Metals and Hard Materials 2007;25:345-50. 
[8] Bilgi E, Camurlu HE, Akgün B, Topkaya Y, Sevinç N. Formation of TiB2 by volume combustion and mechanochemical process. Materials Research Bulletin 2008;43:873-81.

[9] Kumar BA, Murugan N. Metallurgical and mechanical characterization of stir cast AA6061T6-AlNp composite. Materials \& Design 2012;40:52-8.

[10] Bakshi SR, Lahiri D, Agarwal A. Carbon nanotube reinforced metal matrix composites-a review. International Materials Reviews 2010;55:41-64.

[11] FALODUN OE, OBADELE BA, OKE SR, IGE OO, OLUBAMBI PA, LETHABANE ML, et al. Influence of spark plasma sintering on microstructure and wear behaviour of Ti-6Al$4 \mathrm{~V}$ reinforced with nanosized TiN. Transactions of Nonferrous Metals Society of China (English Edition) 2018;28. https://doi.org/10.1016/S1003-6326(18)64637-0.

[12] Mamedov V. Spark plasma sintering as advanced PM sintering method. Powder Metallurgy 2002;45:322-8.

[13] Hungria T, Galy J, Castro A. Spark plasma sintering as a useful technique to the nanostructuration of piezo-ferroelectric materials. Advanced Engineering Materials 2009;11:615-31.

[14] Chen W, Anselmi-Tamburini U, Garay JE, Groza JR, Munir ZA. Fundamental investigations on the spark plasma sintering/synthesis process: I. Effect of dc pulsing on reactivity. Materials Science and Engineering: A 2005;394:132-8.

[15] Feng H, Zhou Y, Jia D, Meng Q. Rapid synthesis of Ti alloy with B addition by spark plasma sintering. Materials Science and Engineering: A 2005;390:344-9.

[16] Falodun OE, Obadele BA, Oke SR, Maja ME, Olubambi PA. Effect of sintering parameters on densification and microstructural evolution of nano-sized titanium nitride reinforced titanium alloys. Journal of Alloys and Compounds 2018;736. https://doi.org/10.1016/j.jallcom.2017.11.140.

[17] Couret A, Molénat G, Galy J, Thomas M. Microstructures and mechanical properties of TiAl alloys consolidated by spark plasma sintering. Intermetallics 2008;16:1134-41.

[18] Gras C, Gaffet E, Bernard F. Combustion wave structure during the MoSi2 synthesis by mechanically-activated self-propagating high-temperature synthesis (MASHS): in situ time-resolved investigations. Intermetallics 2006;14:521-9.

[19] Zhang ZH, Shen XB, Wang FC, Lee SK, Wang L. Densification behavior and mechanical properties of the spark plasma sintered monolithic TiB2 ceramics. Materials Science and 
Engineering: A 2010;527:5947-51.

[20] Oke SR, Ige OO, Falodun OE, Okoro AM, Mphahlele MR, Olubambi PA. Powder metallurgy of stainless steels and composites: a review of mechanical alloying and spark plasma sintering. The International Journal of Advanced Manufacturing Technology 2019;102:3271-90.

[21] Ipekoglu M, Nekouyan A, Albayrak O, Altintas S. Mechanical characterization of B 4 C reinforced aluminum matrix composites produced by squeeze casting. Journal of Materials Research 2017;32:599-605.

[22] Falodun OE, Obadele BA, Oke SR, Maja ME, Olubambi PA. Synthesis of Ti-6Al-4V alloy with nano-TiN microstructure via spark plasma sintering technique. IOP Conference Series: Materials Science and Engineering, vol. 272, 2017. https://doi.org/10.1088/1757899X/272/1/012029.

[23] Amanov A, Urmanov B, Amanov T, Pyun YS. Strengthening of Ti-6Al-4V alloy by high temperature ultrasonic nanocrystal surface modification technique. Materials Letters 2017;196:198-201.

[24] Falodun OE, Obadele BA, Oke SR, Olubambi PA, Westraadt J. Characterization of spark plasma sintered TiN nanoparticle strengthened titanium alloy using EBSD and TKD. Materials Research Bulletin 2019;117:90-5.

[25] TP G, LH M. Mechanical and Wear behaviour of Al6061 reinforced with Graphite and TiC Hybrid MMC's. Materials Research Innovations 2020;24:179-85. 


\section{Figures}
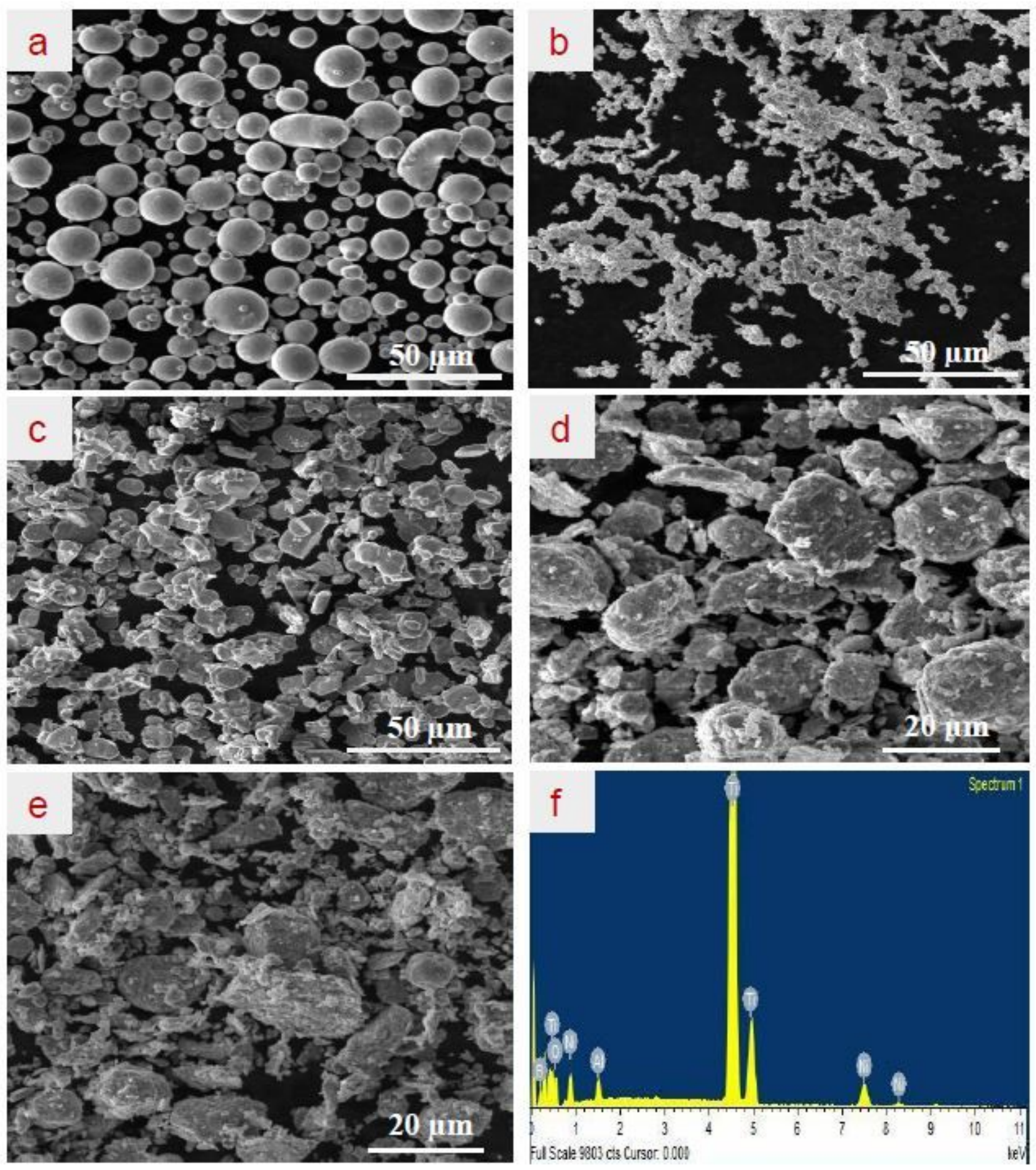

Figure 1

SEM morphology of the powders; (a) Commercial pure titanium, (b) Nickel, (c) Titanium diboride, (d-e) admixed powders of Ti-Ni with 5 and 20 vol.\% TiB2 and (f) EDX of the admixed powders. 

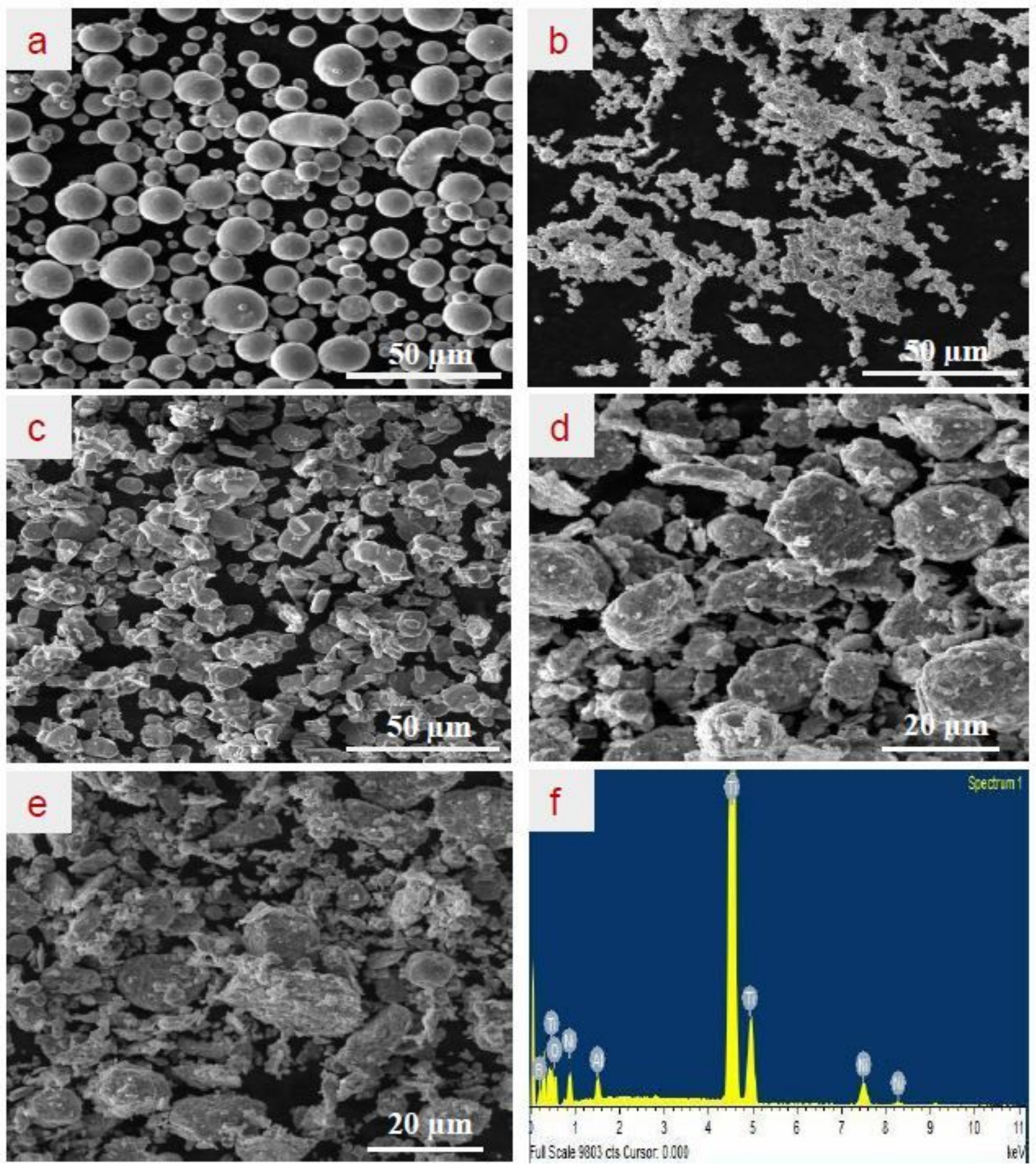

Figure 1

SEM morphology of the powders; (a) Commercial pure titanium, (b) Nickel, (c) Titanium diboride, (d-e) admixed powders of Ti-Ni with 5 and 20 vol.\% TiB2 and (f) EDX of the admixed powders. 


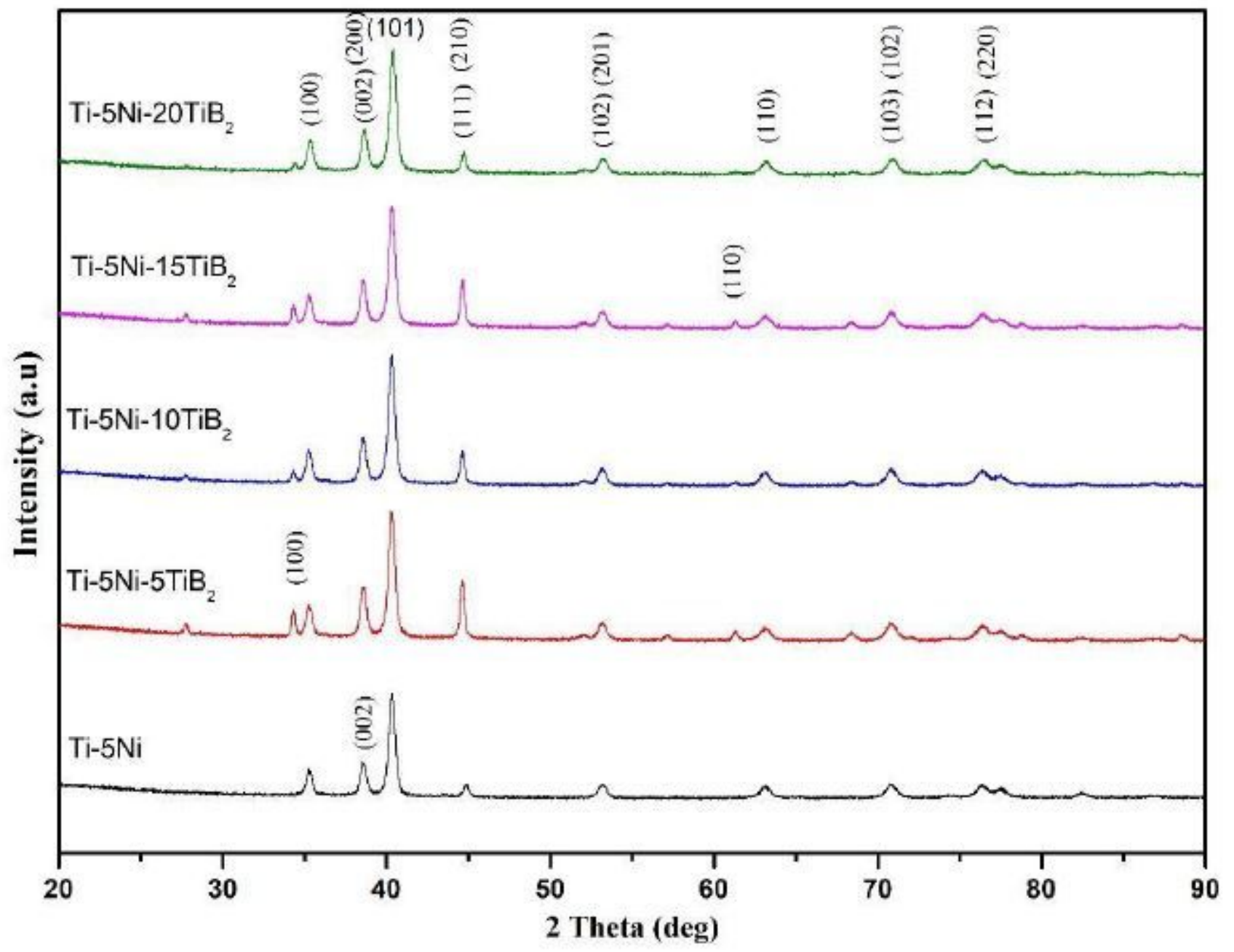

Figure 2

XRD patterns of the admixed composite powders 


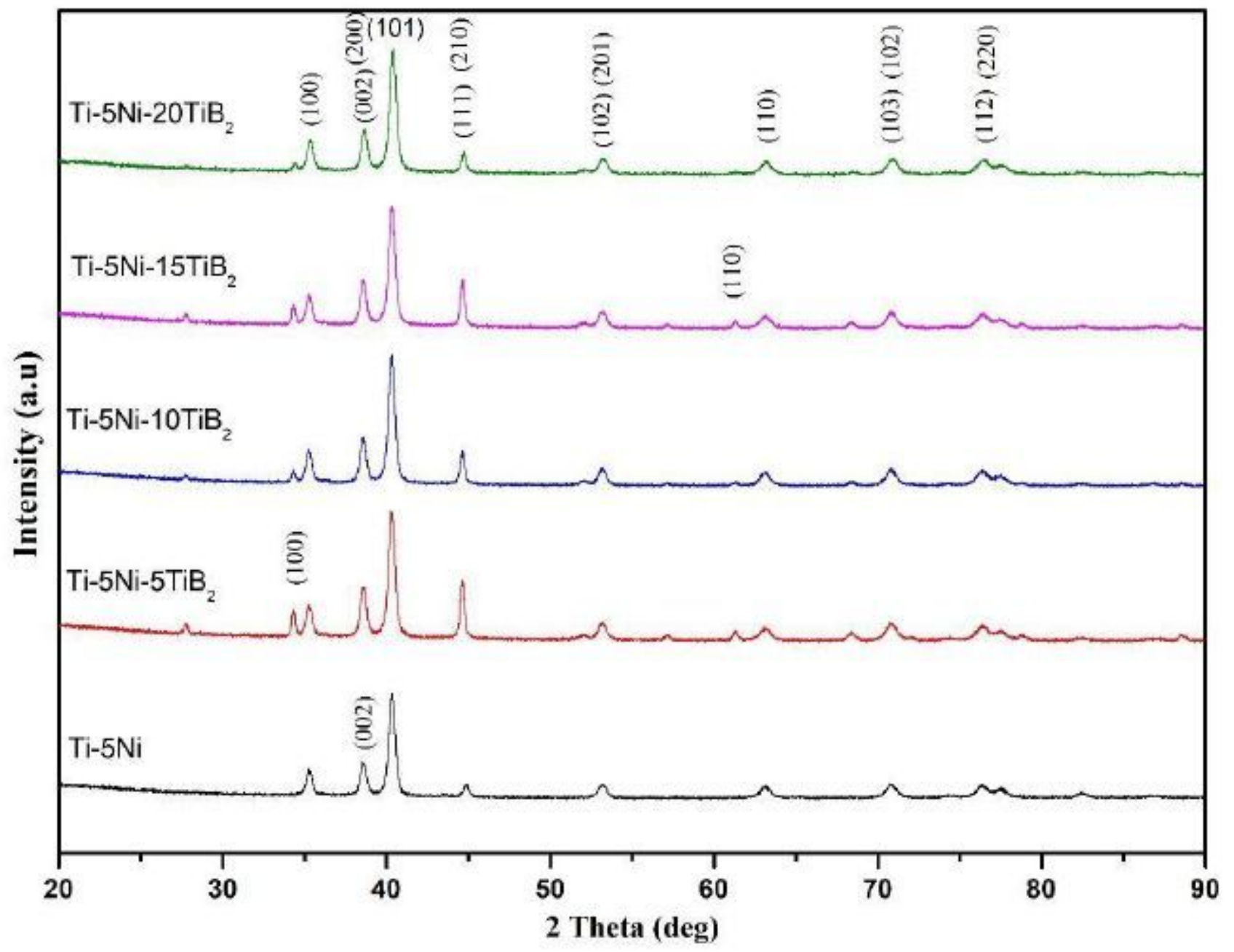

Figure 2

XRD patterns of the admixed composite powders 

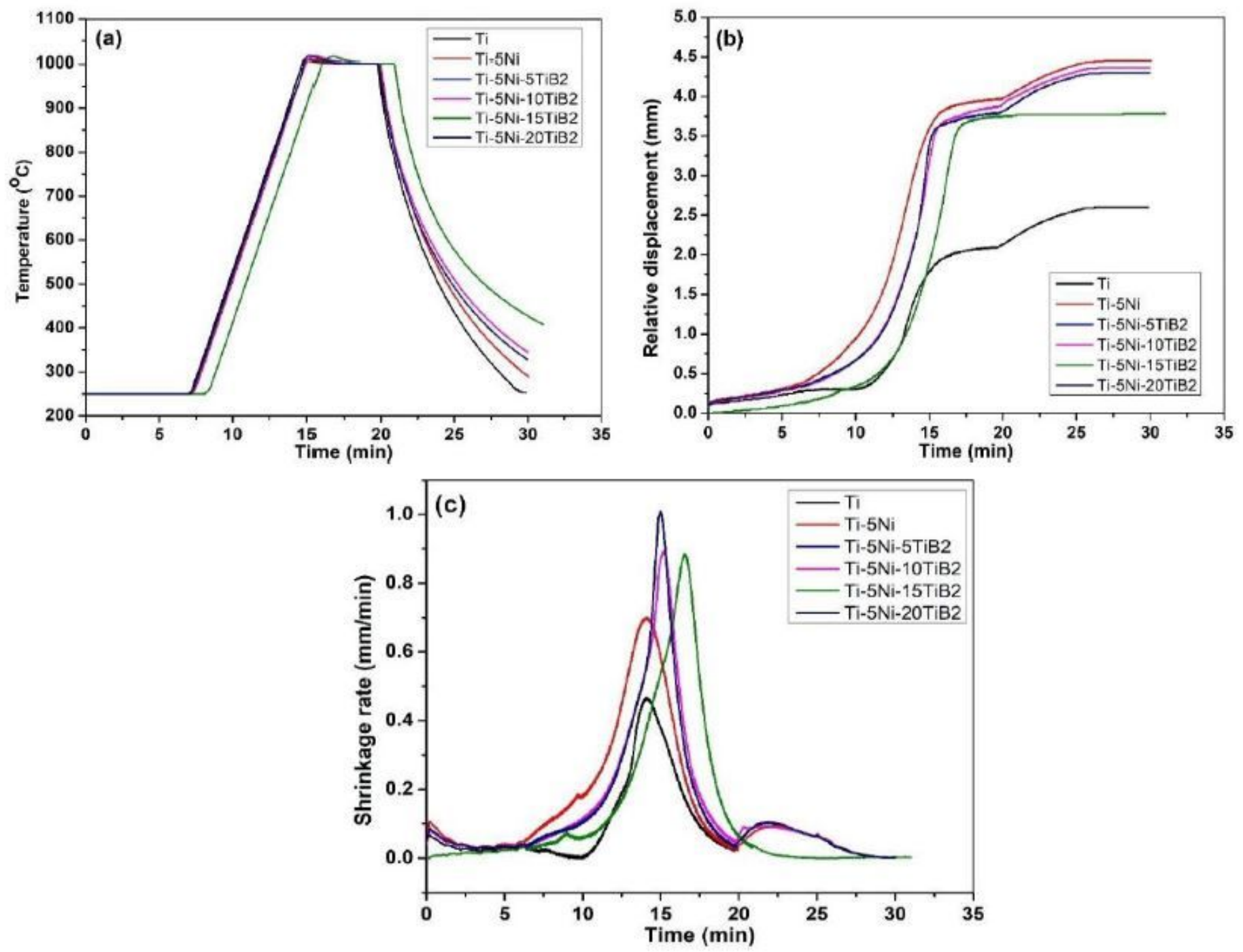

Figure 3

Sintering parameters during SPS process against time: (a) sintering temperature, (b) relative displacement and (c) shrinkage rate. 

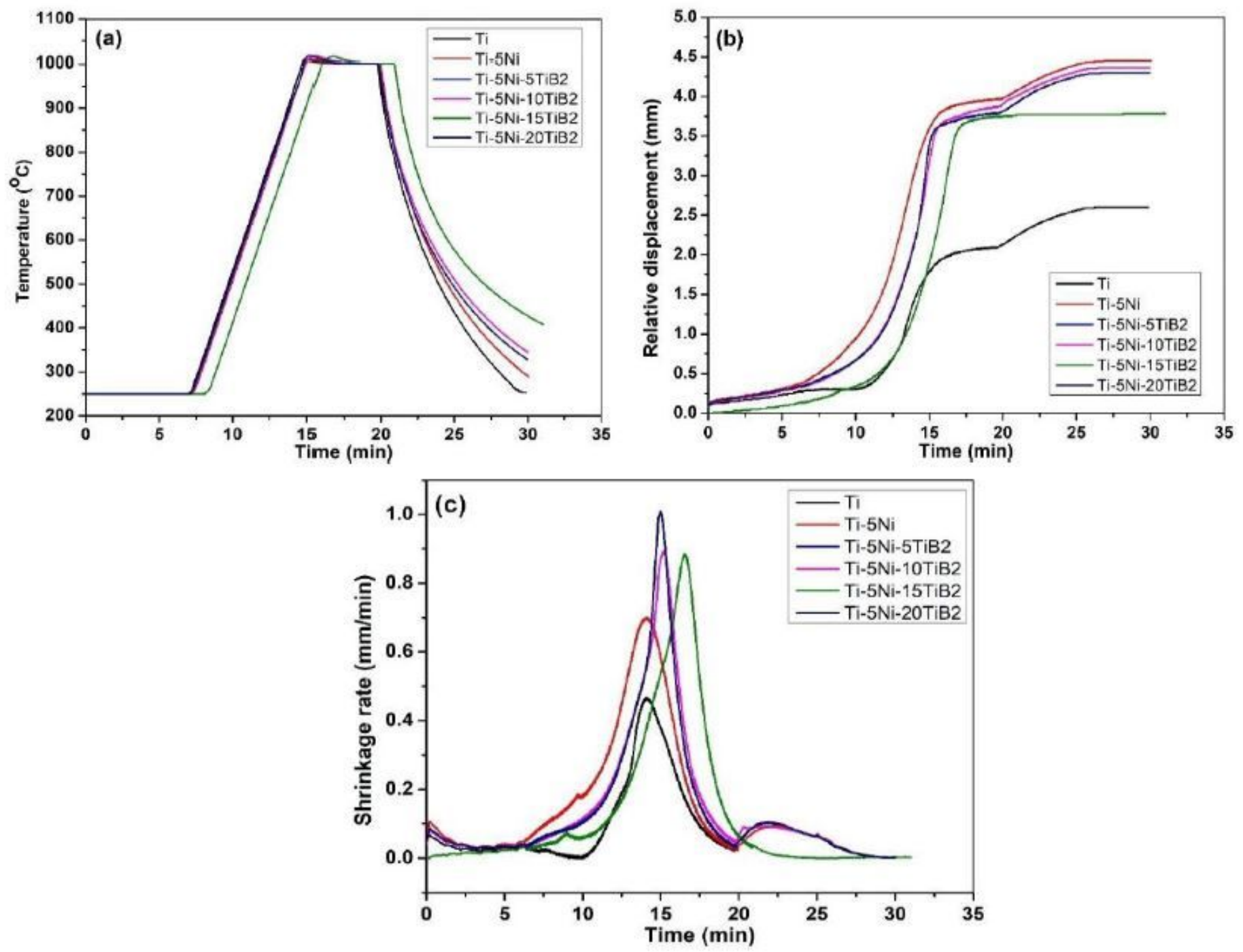

Figure 3

Sintering parameters during SPS process against time: (a) sintering temperature, (b) relative displacement and (c) shrinkage rate. 

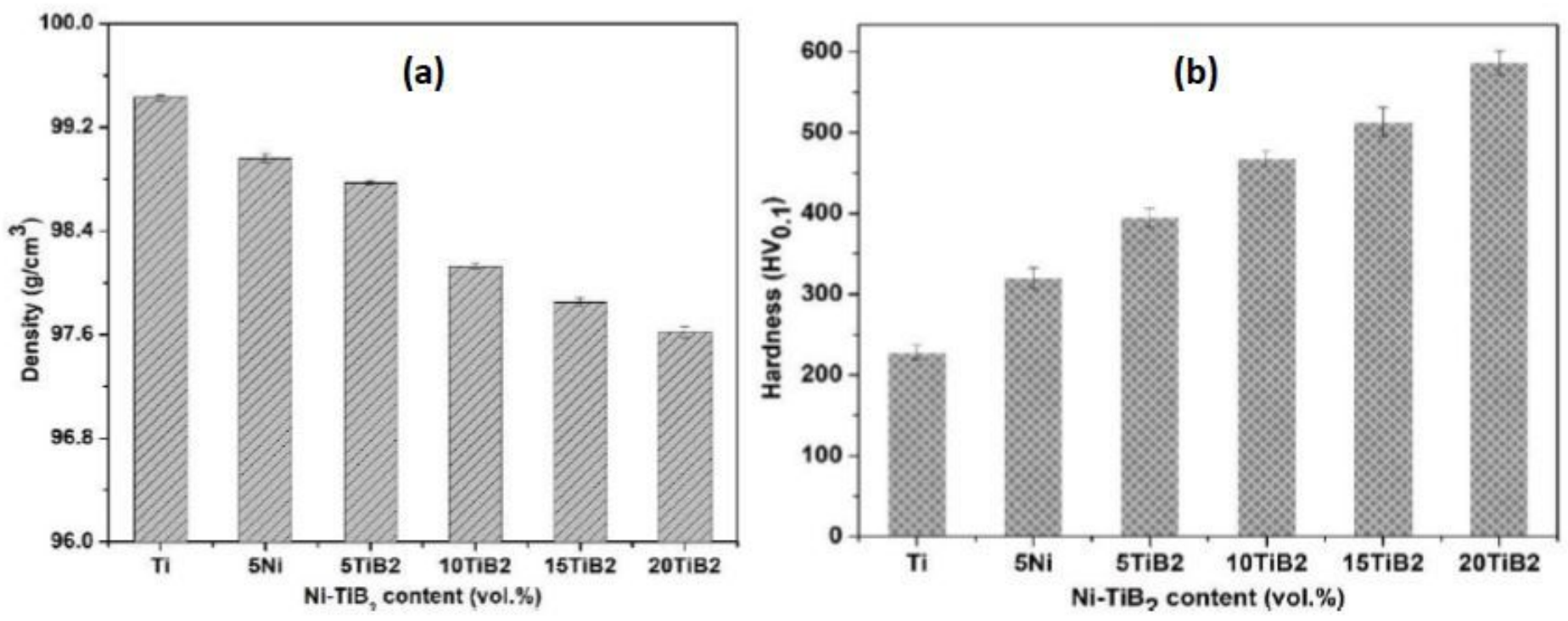

Figure 4

(a) Relative density and (b) Microhardness values of the sintered titanium-based composite.
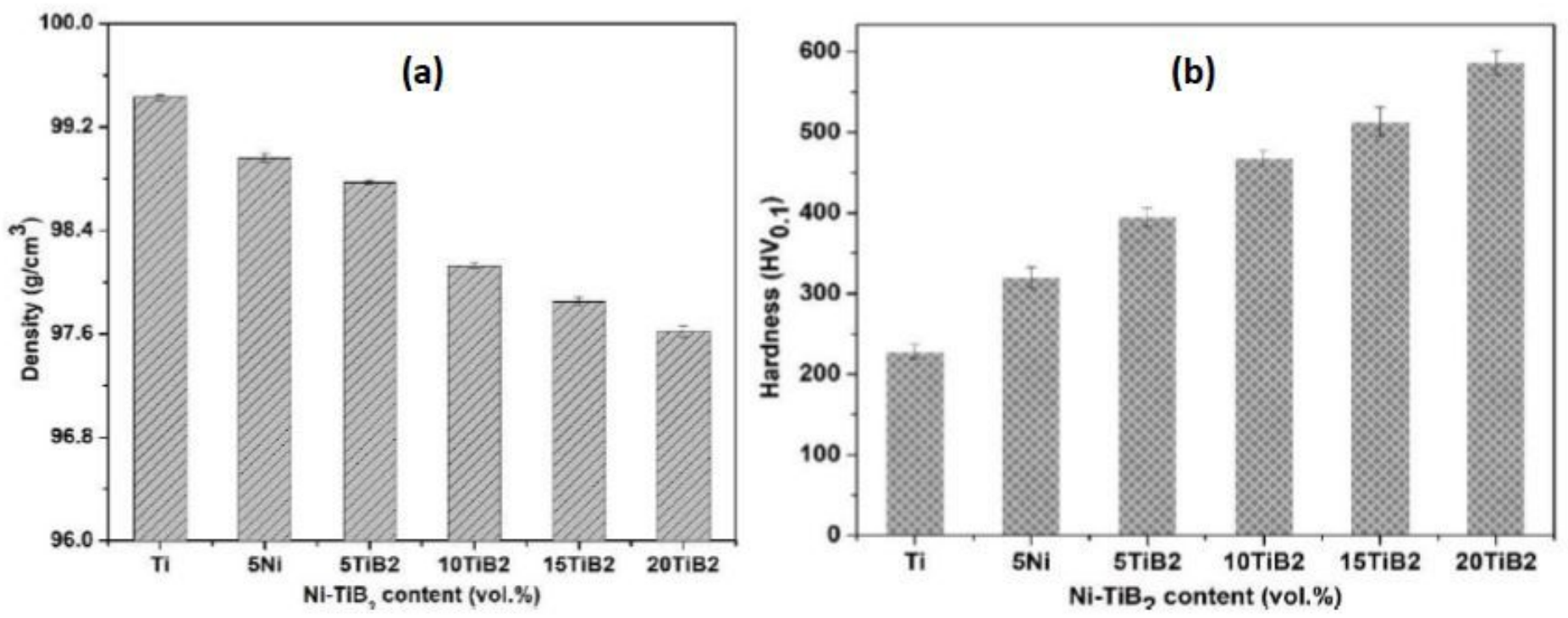

Figure 4

(a) Relative density and (b) Microhardness values of the sintered titanium-based composite. 


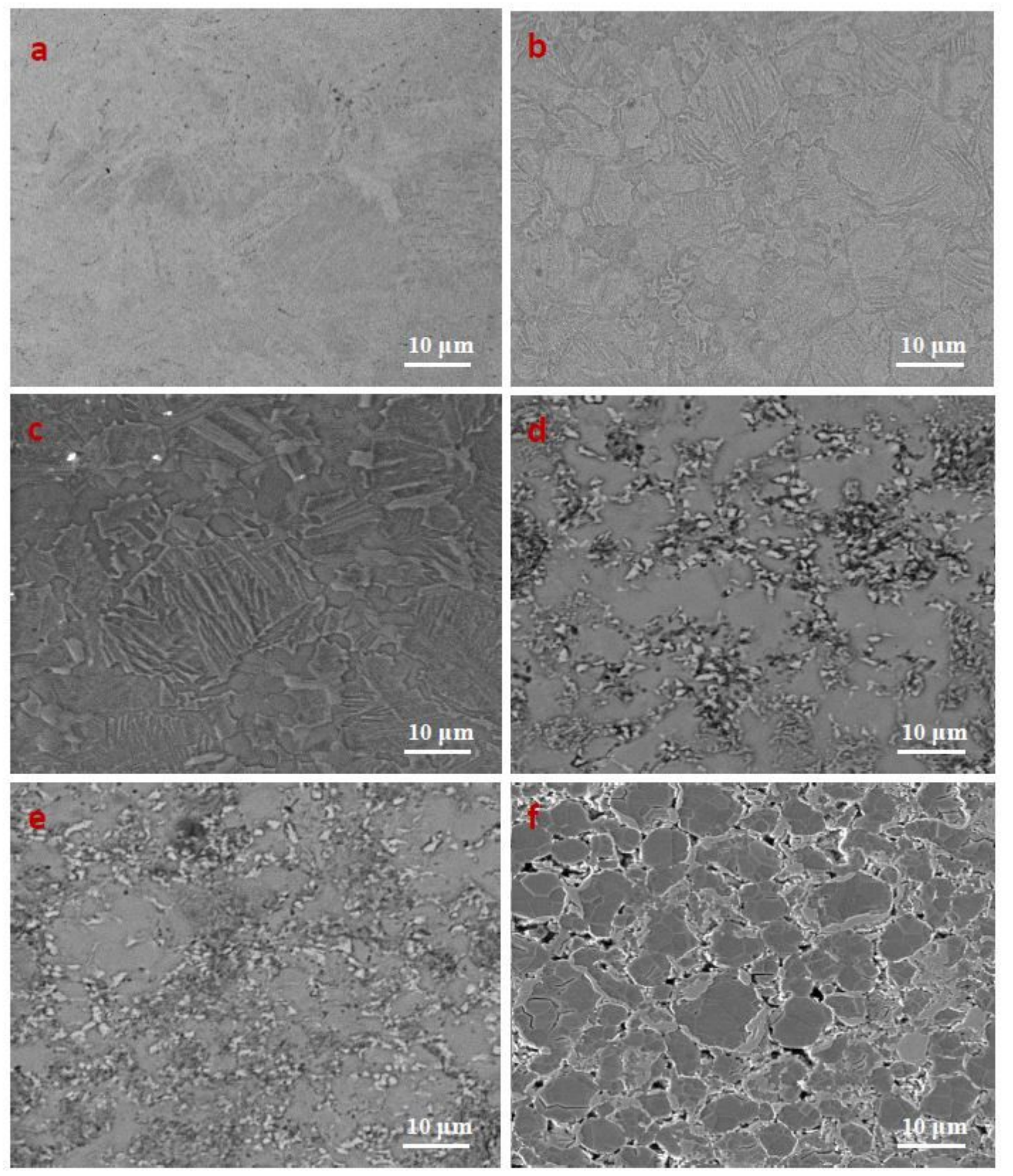

Figure 5

SEM microstructure of sintered composites; (a) Ti alloy, (b) Ti-5 vol.\% Ni, (c) Ti-5 vol.\% Ni-TiB2, (d) Ti-10 vol.\% TiB2, (e) Ti-15 vol.\% TiB2 and (f) Ti-5 vol.\% Ni-20 vol.\% TiB2. 


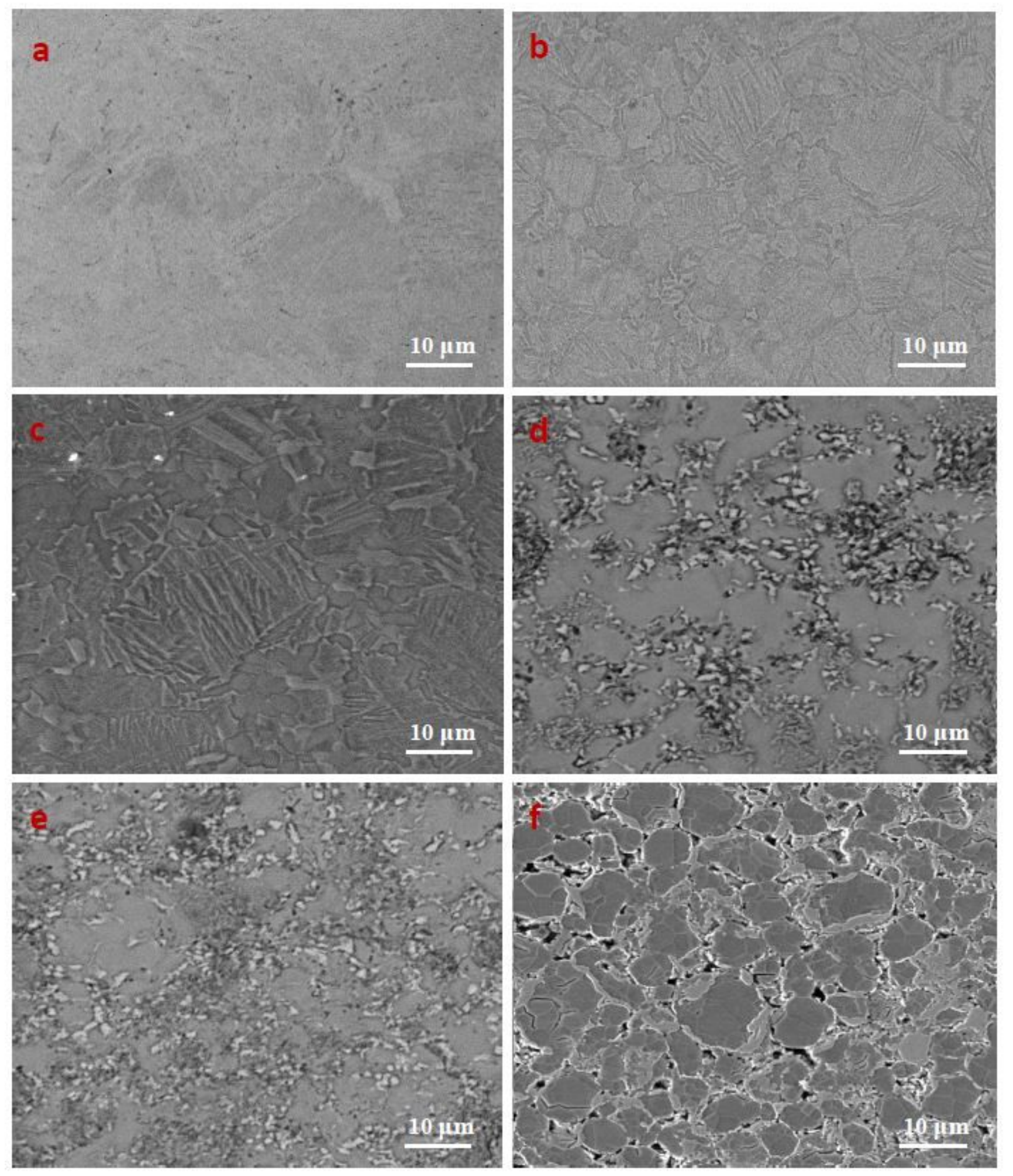

Figure 5

SEM microstructure of sintered composites; (a) Ti alloy, (b) Ti-5 vol.\% Ni, (c) Ti-5 vol.\% Ni-TiB2, (d) Ti-10 vol.\% TiB2, (e) Ti-15 vol.\% TiB2 and (f) Ti-5 vol.\% Ni-20 vol.\% TiB2. 

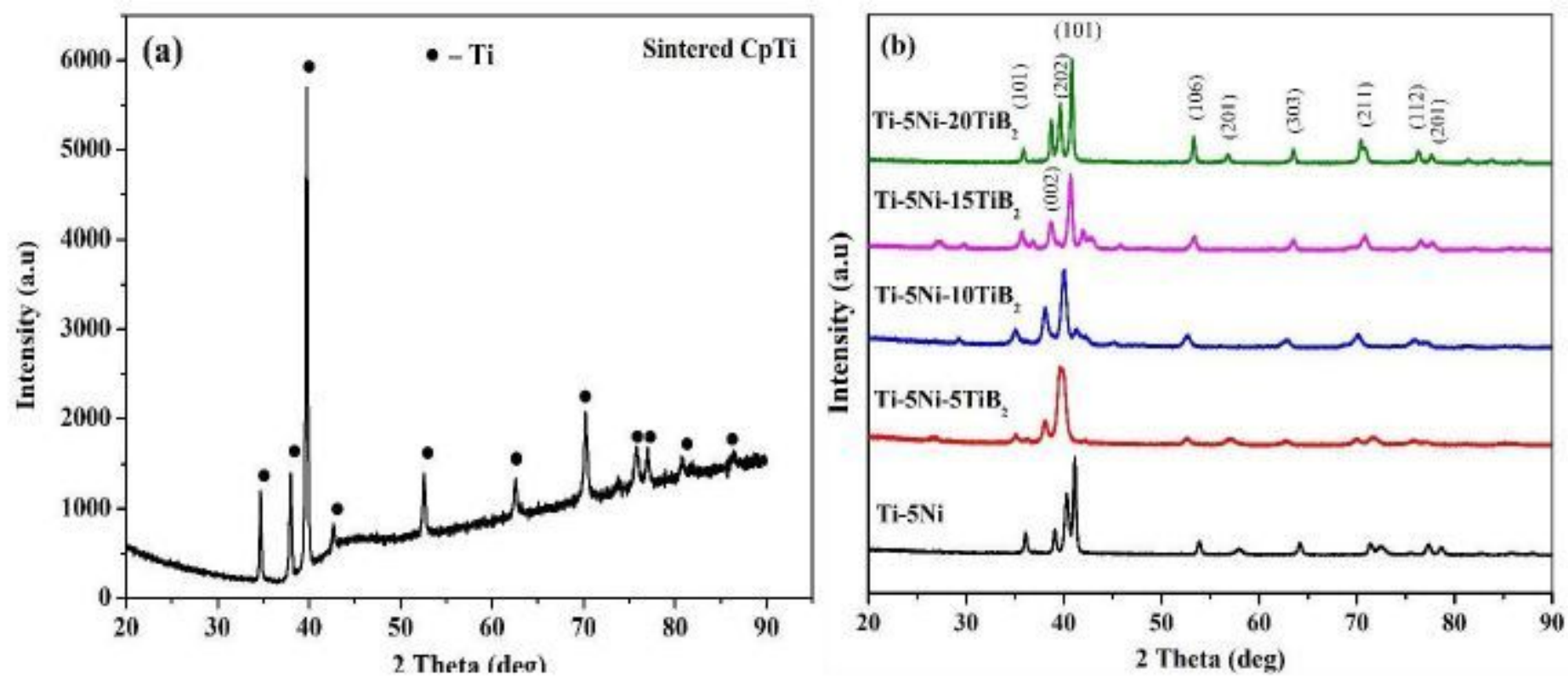

Figure 6

XRD patterns of sintered titanium-based composite: (a) Titanium alloy and (b) varying volume fraction of TiB2.
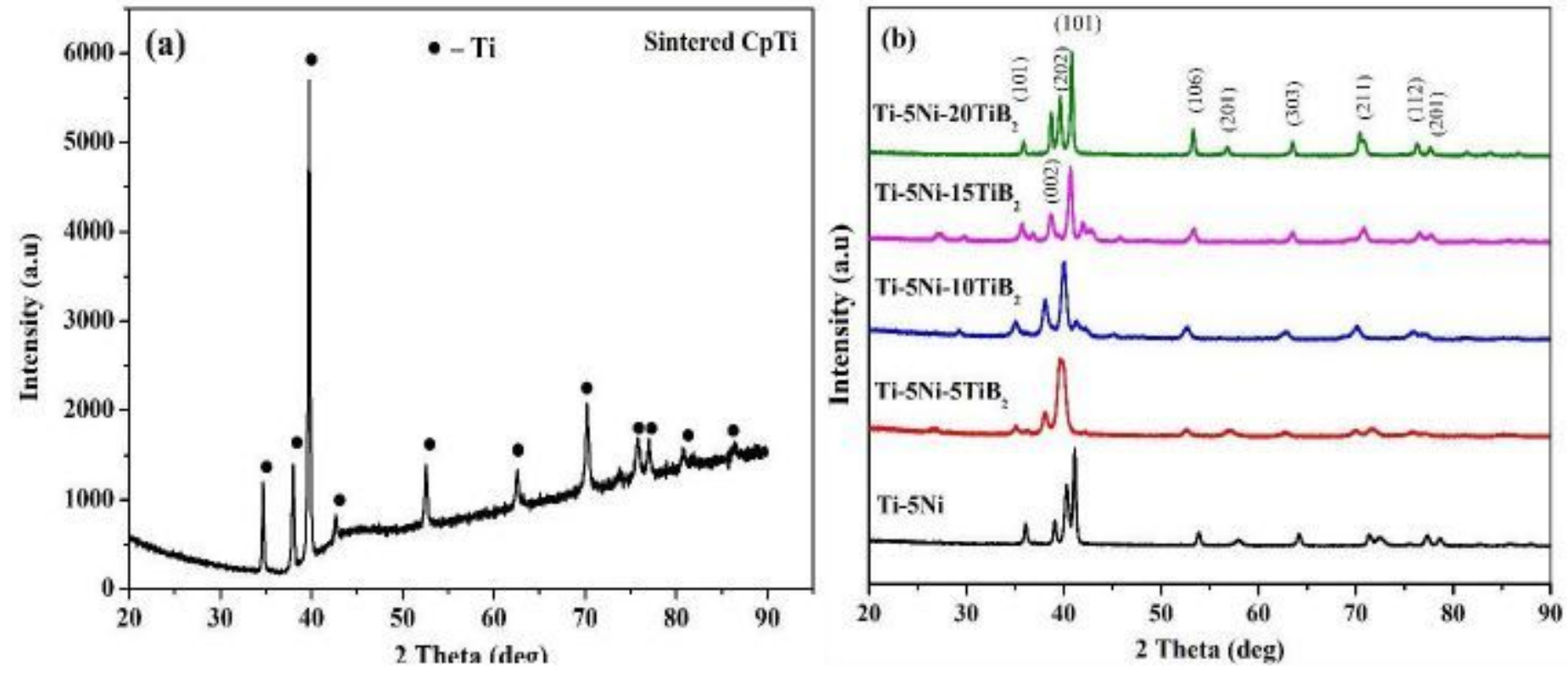

Figure 6

XRD patterns of sintered titanium-based composite: (a) Titanium alloy and (b) varying volume fraction of TiB2. 

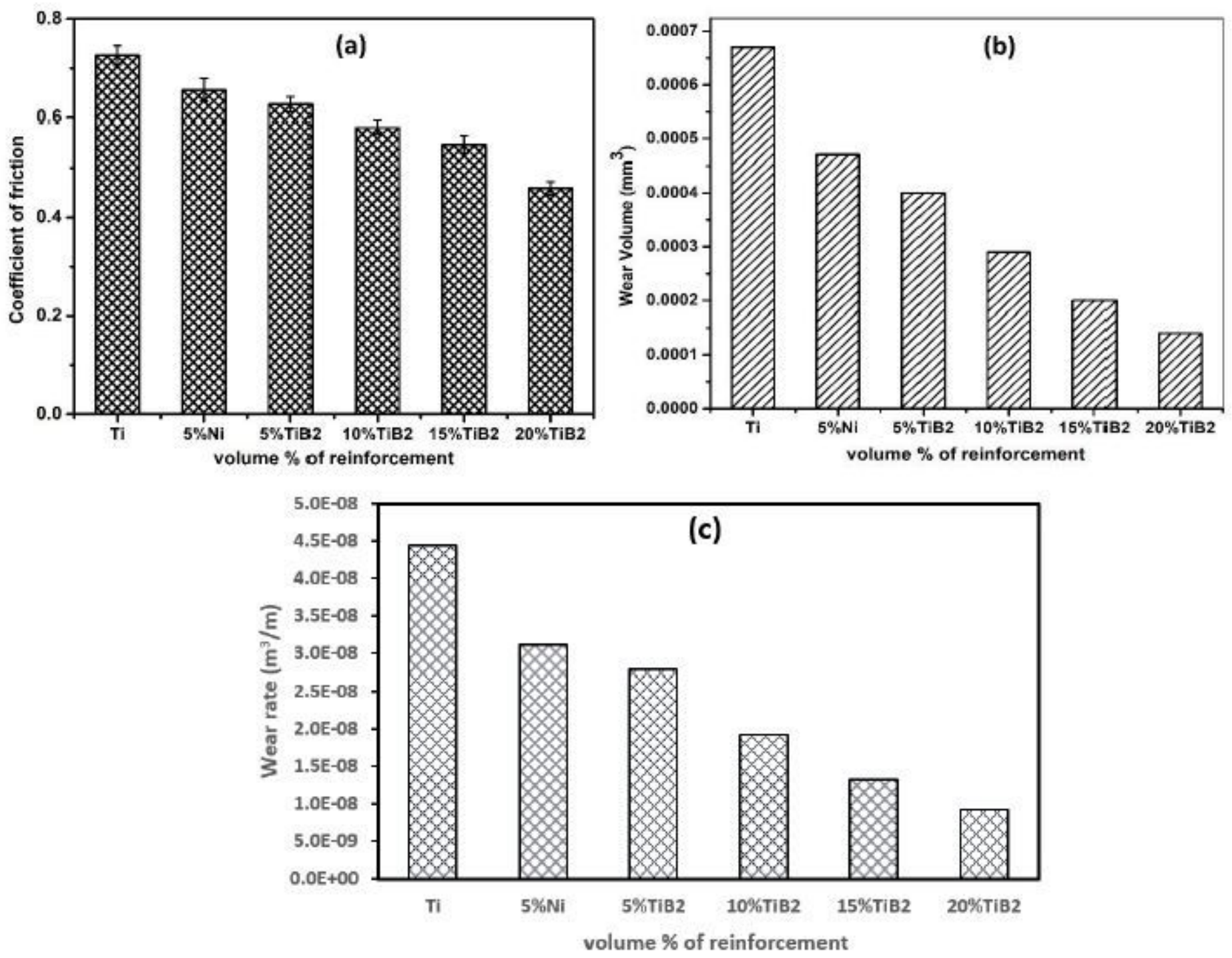

Figure 7

Graph showing the effect of reinforcement: (a) coefficient of friction, (b) wear volume and (c) wear rate 

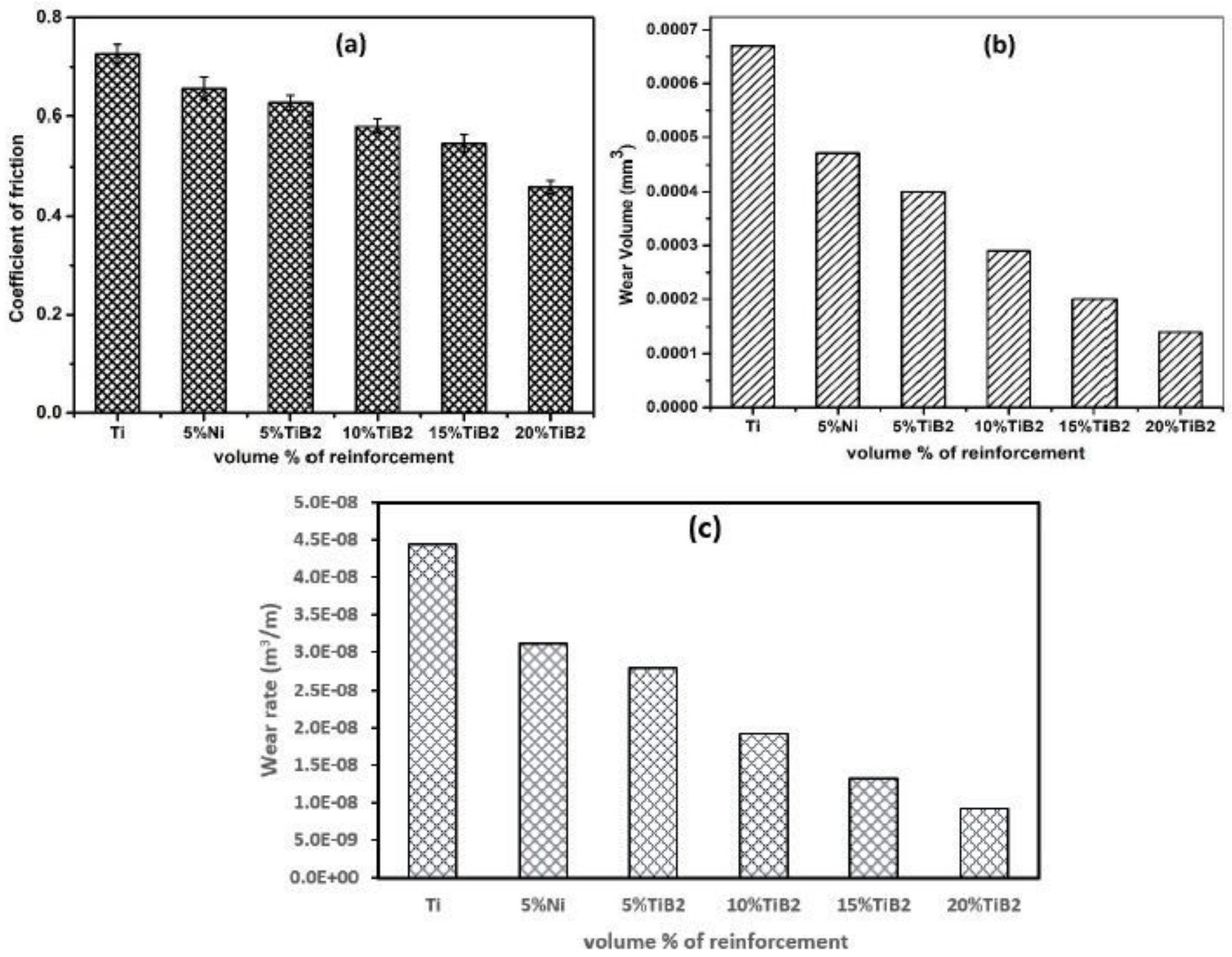

Figure 7

Graph showing the effect of reinforcement: (a) coefficient of friction, (b) wear volume and (c) wear rate 